\title{
PARAGOMINAS SE TORNA EXEMPLO DE SUSTENTABILIDADE COMBATENDO O DESMATAMENTO NA AMAZÔNIA
}

Renato de Lima Alves 1

Gilberto Charlenson Palheta 2

Ocinei Ferreira de Andrade 3

\begin{abstract}
RESUMO
O município foi sinônimo de desmatamento desde a abertura da rodovia Belém-Brasília, na década de 1970. Hoje com aproximadamente 100 mil habitantes, Paragominas é tida como modelo de desenvolvimento sustentável para outras cidades amazônicas, pois a partir de 2008 iniciou-se um novo ciclo de desenvolvimento, auxiliando com políticas públicas de desenvolvimento socioambiental, tendo como refencial teórico LINCOLN PAIVA 2008 que nos esclarece que tais práticas de gestão revolucionam a economia local como novas práticas de proteção ao meio ambiente com o fim do desmatamento e reflorestamento de áreas degradadas com espécies nativas da região amazônica. Nosso objetivo é mostrar como o projeto Município Verde mudou a situação e tornou Paragominas exemplo de sustentabilidade com práticas de Gestão Pública voltada para a sustentabilidade, nos trazendo a reflexão sobre importantes políticas públicas para a manutenção e conservação do meio natural com práticas de respeito ao meio ambiente como forma de fomentar o desenvolvimento econômico com uma Sociedade Sustentável. Tendo como método de estudo em pesquisas de dados governamentais, estatísticas, documentais levando em consideração análises de imagens espaçotemporais de áreas degradadas do município, além de um estudo bibliográfico de dados quantitativos e quantitativos relevante ao plantío de novas árvores e da diminuição exponencial do desmatamento no referido município durante a vigência e pós Programa Município Verde. Constatou-se o impacto direto na preservação do meio ambiente, na economia local e na geração de novas oportunidades de geração de emprego auxiliando desenvolvimento econômico e socioambiental.
\end{abstract}

Palavras Chave: Sustentabilidade. Paragominas. Amazônia.

\section{PARAGOMINAS BECAME SUSTAINABILITY EXAMPLE COMBATING DEFORESTATION IN THE AMAZON}

\begin{abstract}
RESUMO
The city was synonymous with deforestation since the opening of the Belem-Brasilia highway, in the 1970 s today with approximately 100,000 inhabitants, Paragominas is considered model of sustainable development for other Amazonian cities, because from 2008 began a new development cycle, assisting with public policies of environmental development, having as theoretical refencial LINCOLN PAIVA in 2008 makes it clear that such management practices revolutionize the local economy as new practices to protect the environment with the aim of deforestation and reforestation of degraded areas species

\footnotetext{
${ }^{1}$ Graduando em Geografia, Faculdade Ipiranga. renato.agrogeo@hotmail.com.

2'Graduando em Geografia, Instituto Federal do Pará IFPA. rilberto.ufpa.geografia@gmail.com.

${ }^{3}$ Graduando em Geografia, Faculdade Ipiranga. ocineiandrade2013@gmail.com.
} 
native to the Amazon region. Our goal is to show how the Green City project changed the situation and made Paragominas example of sustainability with Public Management practices geared towards sustainability, bringing us to reflect on major public policy for the maintenance and conservation of the natural environment with respect to practices in half environment as a way to foster economic development with a Sustainable Society. With the method of study on government survey data, statistics, documentary taking into account analysis of spatio-temporal images of degraded areas of the city, as well as a bibliographical study of quantitative and quantitative data relevant to the planting of new trees and the exponential decrease in deforestation in the municipality during the term and after Green city program. It found the direct impact on the preservation of the environment, the local economy and generating new opportunities for job creation helping economic and environmental development.

Keywords: Sustainability. Paragominas. Amazon.

\section{PARAGOMINAS CONVIRTIÓ EJEMPLO SOSTENIBILIDAD LUCHA CONTRA LA DEFORESTACIÓN EN EL AMAZONAS}

\section{RESUMO}

La ciudad era sinónimo de deforestación desde la apertura de la carretera Belém-Brasilia, en la década de 1970 hoy con aproximadamente 100 mil habitantes, Paragominas se considera modelo de desarrollo sostenible para otras ciudades amazónicas, porque a partir de 2008 se inició una nueva ciclo de desarrollo, ayudando con las políticas públicas de desarrollo ambiental, teniendo como teórico PAIVA LINCOLN refencial en 2008 pone de manifiesto que este tipo de prácticas de gestión de revolucionar la economía local como nuevas prácticas para proteger el medio ambiente con el objetivo de la deforestación y la reforestación de áreas degradadas especies nativas de la región amazónica. Nuestro objetivo es mostrar cómo el proyecto Ciudad Verde ha cambiado la situación y hacía Paragominas ejemplo de sostenibilidad con las prácticas de gestión públicas orientadas hacia la sostenibilidad, llevándonos a reflexionar sobre la política pública importante para el mantenimiento y conservación del medio natural con respecto a las prácticas en el medio medio ambiente como una manera de fomentar el desarrollo económico con una sociedad sostenible. Con el método de estudio sobre datos de la encuesta del gobierno, estadística, documental teniendo en análisis de cuentas de las imágenes espacio-temporales de las zonas degradadas de la ciudad, así como un estudio bibliográfico de datos cuantitativos y cualitativos relacionados con la plantación de nuevos árboles y la disminución exponencial de la deforestación en el municipio durante el plazo y después del programa Ciudad Verde. Se encontró el impacto directo en la preservación del medio ambiente, la economía local y la generación de nuevas oportunidades para la creación de empleo para ayudar el desarrollo económico y ambiental.

Palabras clave: Sostenibilidad. Paragominas. Amazon. 


\section{INTRODUÇÃO}

A cidade de Paragominas, no leste do Pará, se encontra nas seguintes coordenadas geográficas de Latitude: $2^{\circ} 59^{\prime} 51^{\prime \prime}$ Sul Longitude: $47^{\circ} 21^{\prime} 13^{\prime \prime}$ Oeste. $O$ município foi sinônimo de desmatamento desde a abertura da rodovia Belém-Brasília, na década de 1970. Hoje com aproximadamente 100 mil habitantes, Paragominas é tida como modelo de desenvolvimento sustentável' para outras cidades amazônicas, pois a partir de 2008 iniciou-se um novo ciclo de desenvolvimento, auxiliando com políticas públicas de desenvolvimento socioambiental, tais práticas de gestão revolucionou a economia local com manejo florestal e reflorestamento iniciou-se com espécies nativas da região amazônica como cedro, mogno, darco, maçaramduba, timborana, paricá, samaúma e eucalipto a única planta não nativa da região. Com o projeto Município Verde mudou a situação e tornou de Paragominas exemplo de sustentabilidade na prática.

Esse resumo tem como objetivo mostrar as práticas de Gestão Pública voltada para a sustentabilidade com o reflorestamento e manejo florestal, educação ambiental, práticas de respeito ao meio ambiente como forma de fomentar o desenvolvimento econômico com uma Sociedade Sustentável ${ }^{2}$, tendo como metodologias análises imagens espaço-temporais do desmatamento do município além de um estudo bibliográfico de dados quantitativos e quantitativos relevante ao plantio de novas árvores e da diminuição exponencial do desmatamento no referido município.

\section{ALGUMAS INFORMAÇÕES DO MUNICÍPIO DE PARAGOMINAS}

\subsection{Localização:}

O município de Paragominas, possui aproximadamente $20.000 \mathrm{Km} 2$ de área territorial, formada por extensas florestas e belezas naturais, reflorestamentos, campos e plantios agrícolas. O município ocupa uma posição geográfica estratégica que confere vantagens inquestionáveis aos investidores devido a facilidade de escoamento da produção através da rodovia Belém-Brasília 010 podendo alcançar o 
posto de Itaqui no Maranhão pela ferrovia de Carajás ou através da Hidrovia do Capim, o porto de Vila do Conde no Pará, porto brasileiro mais próximo em milhas náuticas dos mercados consumidores da Europa, Estados Unidos e Caribe.

Figura 1: Localização de Paragominas

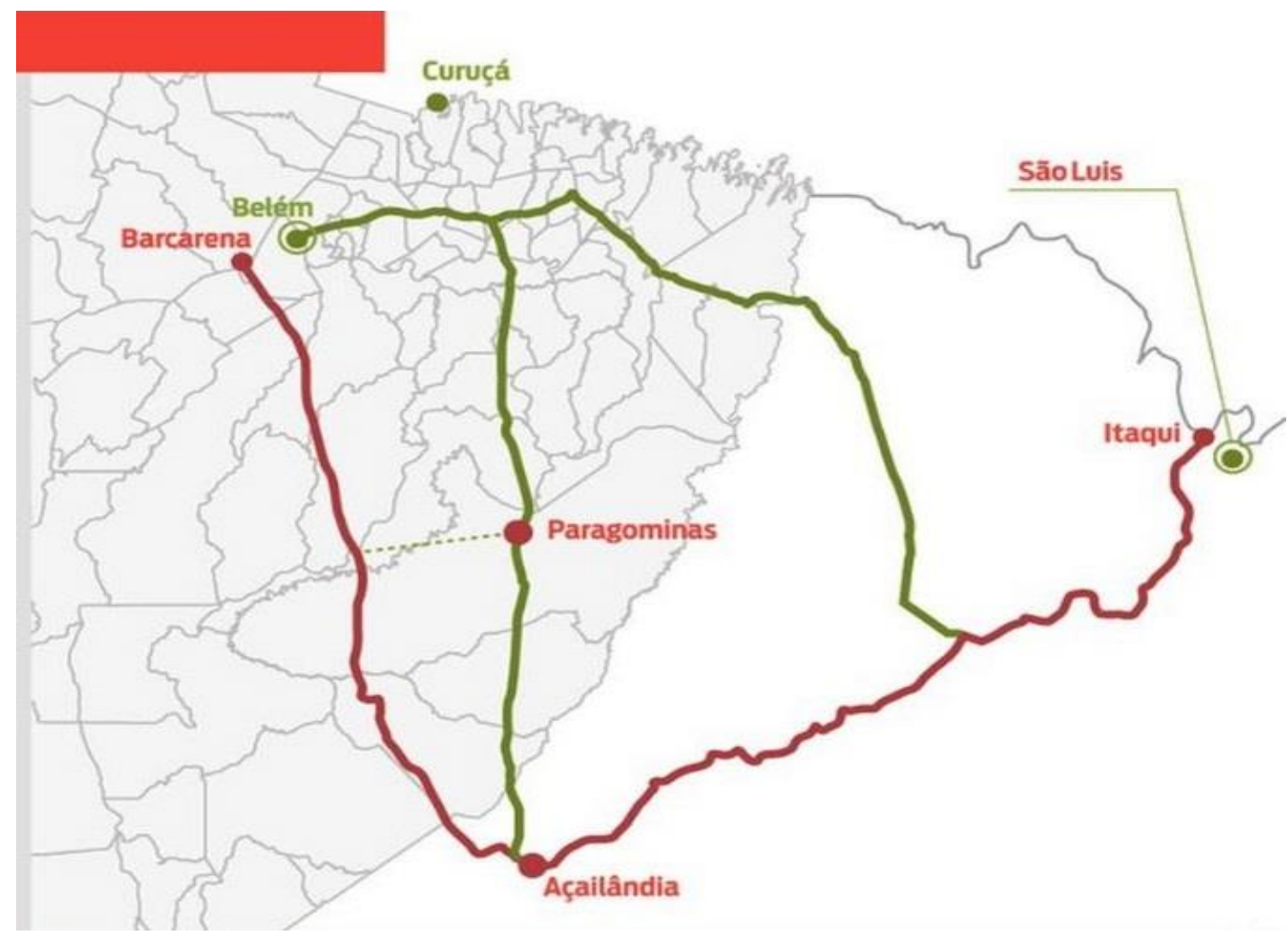

Localização do Município de Paragominas, fonte: Jornal Diário do Pará, 2009

\section{DESCRIÇÃO DO PROJETO DE POLITICA PÚBLICA MUNICÍPIO VERDE}

O prefeito da cidade de Paragominas conseguiu a assinatura de 51 entidades locais para o Pacto pelo Desmatamento Zero, o qual acabou com o desmatamento, implantou a educação ambiental para 30 mil alunos das escolas e regularizou terras do município. O maior desafio foi gerar riqueza sem desmatar, a partir de fórmulas criativas de utilização das áreas disponíveis e garantir o desenvolvimento local sustentável. Até 2008 , a cidade já tinha perdido $43 \%$ de sua área de floresta por conta das atividades locais como madeireiras, movelarias e sobretudo carvoarias que 
provocavam o desmatamento e poluição ambiental através dessas práticas que não eram regularizadas e/ou fiscalizadas por órgãos competentes.

Com este Pacto pelo meio ambiente, a cidade contou com um programa de reflorestamento que plantou cerca de 10 mil árvores por ano $(2008,2009)$, por meio de processos de produção sustentável (socialmente justo, sem o uso de trabalho escravo ou infantil e sem recursos provenientes do desmatamento). Chegando segundo o Prefeito a 60 milhões de árvores (Com auxílios de empresas instaladas no município, sobretudo as mineradoras) A partir de sua implementação, Paragominas foi o primeiro município brasileiro a sair da lista do Ministério do Meio Ambiente dos municípios que mais desmatam na Amazônia (o segundo foi retirado em 2011).

Figura 2: Carvoarias

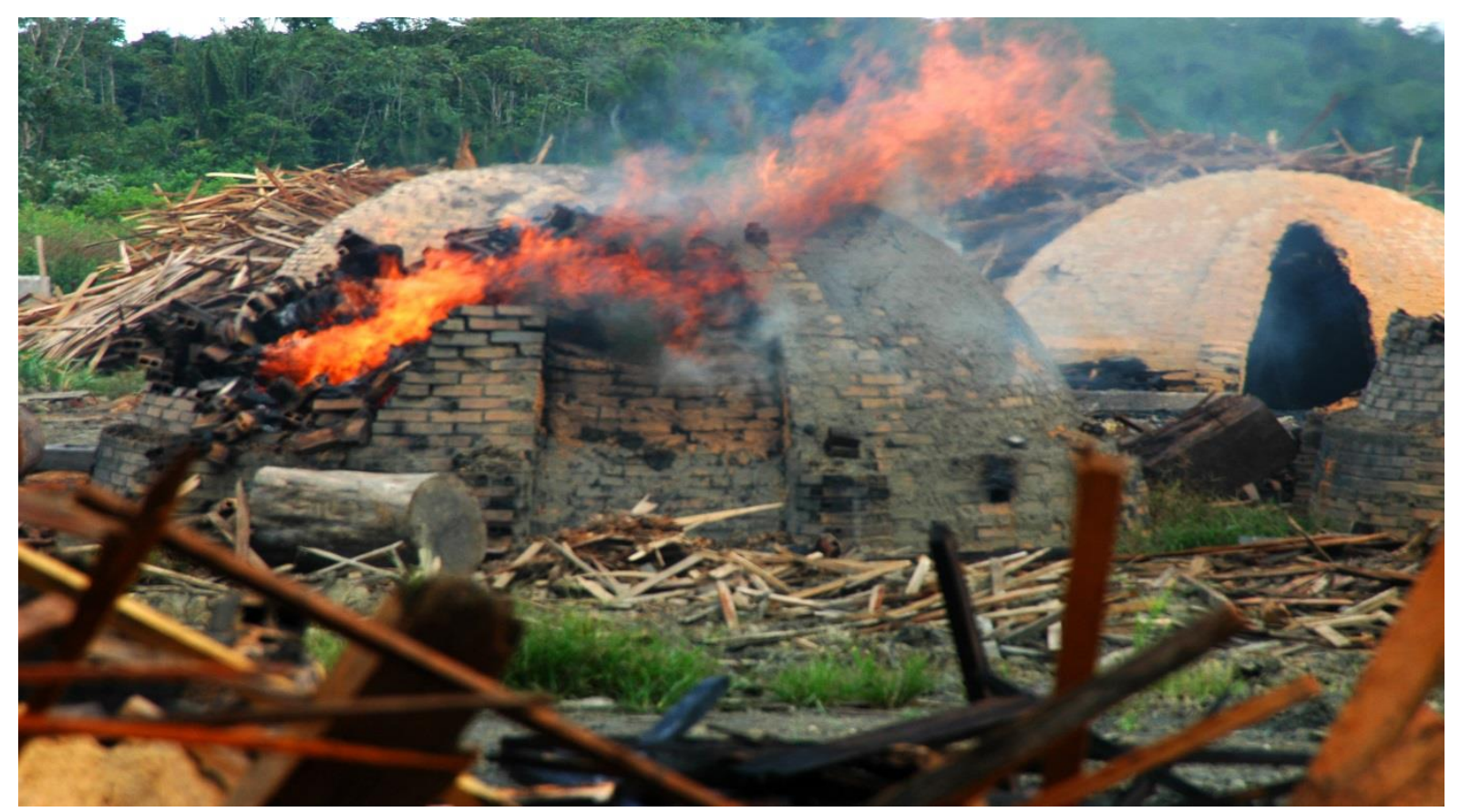

Carvoaria ilegal, destruída pelo Ibama e PF, Paragominas, Pará. Fonte: (Sérgio Abranches) 2008

LINCOLN PAIVA 2008, p. 7 demostra a importância e a proteção que a sociedade necessita ter para com o meio ambiente, para que assim gerações futuras tenham asseguradas um meio ambiente mais saudável e responsável.

As Mudanças Climáticas Globais e Locais (GLOCAL) nunca estiveram tão eminentes. A necessidade de uma ação contínua e participativa, buscando 
soluções imediatas e a longo prazo, já é conhecida. É chegada finalmente a hora da implementação. A parceria entre sociedade civil, poder público e setores privados é a tônica principal para o enriquecimento e a materialização dos debates. Todos podem e devem se envolver com a temática socioambiental, não temos mais alternativas. $O$ meio ambiente, ecologicamente equilibrado, é um bem de uso comum do povo e fundamental para a sadia qualidade de vida.

Assim voga o artigo 225 da nossa Constituição Federal, citando o poder público e a coletividade o dever de defendê-lo e preservá-lo para as presentes e futuras gerações pois, cuidar do meio ambiente é cuidar de nós mesmos. A responsabilidade é coletiva - difusa, pertence a cidadãs e cidadãos; coerentes na práxis ambiental, atuando, contratando, consumindo e produzindo ações, produtos e serviços que façam parte de um Universo Solidário e Sustentável.

\section{DIAGNÓSTICO DO MUNICÍPIO}

A primeira atividade da implantação propriamente dita do projeto foi um extenso trabalho de diagnóstico. Era preciso conhecer o tamanho exato do problema antes de se decidir combatê-lo. Para alcançar o objetivo, a prefeitura iniciou um monitoramento da situação documental das propriedades rurais do município para saber como estavam, em termos legais, essas propriedades. Isso permitiu, no longo prazo, a concessão de certificados aos agricultores e produtores da cidade.

Também no campo, a transformação da rotina de produção começou a tomar corpo. Produtores foram capacitados a reduzir o desmatamento e a recuperar as áreas degradadas. Eles aprenderam a otimizar o cultivo em regiões já desmatadas o que dispensou a necessidade de novas derrubadas de floresta - e a desenvolverem sua produção em harmonia com a floresta nativa. 


\section{SUSTENTABILIDADE, UMA CAUSA DE IMPACTO MUNDIAL-HISTÓRICO}

Entre 1987 a 1992, a comissão Brundtland, da ONU, lançou o relatório Nosso Futuro Comum, coordenada por Gro Brundtland, primeira-ministra da Noruega. O conceito desse relatório era justamente a sustentabilidade, chamando a atenção para problemas como, a sobrevivência humana, aquecimento global e ameaças à biodiversidade e camada de ozônio, enfatizando a relação de questões socioeconômica e ambiental, bem como a responsabilidade para com as gerações futuras. A repercussão desse documento gerou cinco anos depois a Conferência das Nações Unidas sobre o Meio Ambiente e Desenvolvimento Eco 92.

Em 1997, foi criado o protocolo de Kyoto a partir da Convenção Quadro, que nasceu na Eco-92. O protocolo de Kyoto surgiu como esforço coletivo para combater o aquecimento global. Sugerindo que as nações industrializadas se comprometessem em reduzir em $5,2 \%$ seus níveis de emissão de dióxido de carbono (medidos em 1990) até 2008, 2012.

\section{OBJETIVOS DO PROGRAMA MUNICÍPIO VERDE DE PARAGOMINAS}

- Apoiar a redução do desmatamento e degradação florestal

- Promover uma nova economia rural com base na floresta e no uso intensivo da agropecuária

- Melhorar a governança e promover o empoderamento local como mostra o seguinte exemplo: (nos últimos três anos, o município plantou 55 milhões de árvores), pecuária e agricultura sustentáveis (investe na fertilidade do solo em vez de avançar sobre a mata), educação ambiental e manejo florestal (ação que minimiza o impacto sobre a floresta na retirada das toras com relevância econômica). 


\section{O QUE É GESTÃO AMBIENTAL}

\subsection{CONCEITO}

Gestão ambiental é um sistema de administração empresarial e/ou governamental que dá ênfase na sustentabilidade. Desta forma, a gestão ambiental visa o uso de práticas e métodos administrativos de reduzir ao máximo o impacto ambiental das atividades econômicas nos recursos da natureza, que neste trabalho estamos tendo como exemplo de gestão pública o município de Paragominas, nordeste do Pará.

\subsection{MÉTODOS E OBJETIVOS PRINCIPAIS DA GESTÃO AMBIENTAL EM PARAGOMINAS:}

- Uso de recursos naturais de forma racional.

- Aplicação de métodos que visem a manutenção da biodiversidade

- Adoção de sistemas de reciclagem de resíduos sólidos.

- Utilização sustentável de recursos naturais.

- Criação de produtos que provoquem o mínimo possível de impacto ambiental.

- Uso de sistemas que garantam a não poluição ambiental. Exemplo: sistema carbono zero.

- Criação de programas de incentivo fiscal à empresas que se comprimetam a reflorestar áreas degradas provenientes de setores produtivos do município de Paragominas, como por exemplo: mineradoras, movelarias, pecuária e agricultura.

De acordo com Dallas (2009, p. 64) O cenário competitivo do futuro será determinado pelas novas regras criadas pelos governos. O governo aqui tem um papel importante nesse processo em prol da sustentabilidade. 
Figura 3: exemplo de reflorestamento

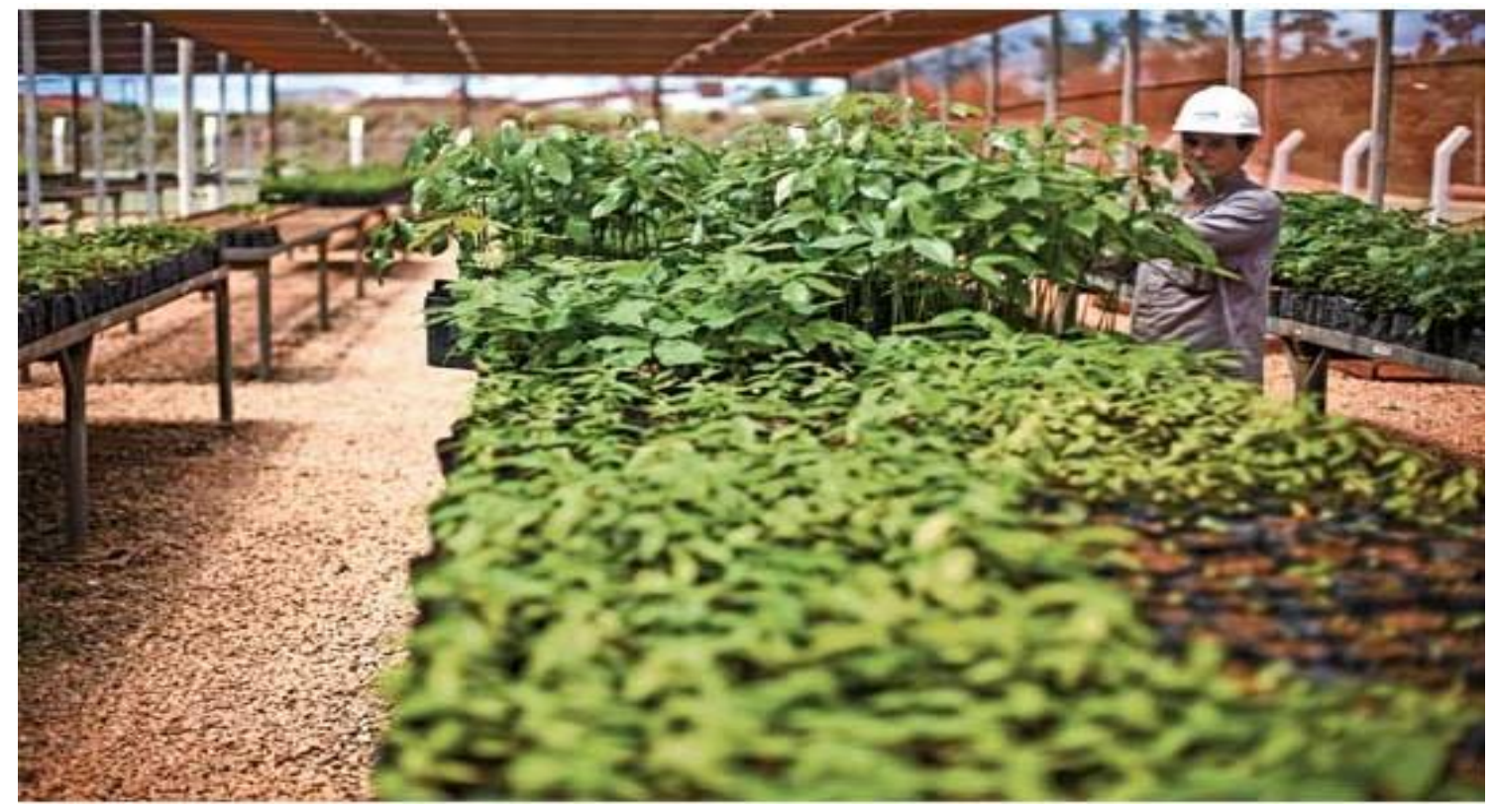

As iniciativas ambientais no município paraense envolve uma série de projetos públicos e privados. A mineradora Hydro, que extrai bauxita dentro da área da cidade, conta com um viveiro de mudas nativas para o reflorestamento das faixas de terras já exploradas. Foto: Rodrigo Baleia 2010.

As empresas devem ser visto como uma oportunidade de negócio, como diz o escritor e ativista ambiental Paul Hawker, o futuro pertence aqueles que entendem que fazer mais com menos é agir com compaixão, É próspero e duradouro, mais inteligente e até competitivo. Dallas (2009, p.65) entende que resolver essas questões não é fácil, pois estão em jogo custos econômicos e mudanças pessoais.

\subsection{IMPORTÂNCIA PARA AS EMPRESAS}

adoção de gestão ambiental é importante para uma empresa por diversos motivos. Em primeiro lugar porque ela associa sua imagem ao da preservação ambiental, melhorando no mercado as imagens das marcas de seus produtos. Empresas que adotam este sistema conseguem reduzir seus custos, evitando desperdícios e reutilizando materiais que antes eram descartados. Empresas com 
gestão ambiental melhoram suas relações comerciais com outras empresas que também seguem estes princípios.

\section{INSTITUIÇÕES ENVOLVIDAS NO PROJETO}

- Prefeitura de Paragominas

- Signatários do Pacto de Paragominas

- Instituto de Terras do Pará (ITERPA)

- Programa Terra Legal

- Sindicato dos Produtoes Rurais de Paragominas

- Secretaria do Meio Ambiente do Estado do Pará (SEMA-PA)

- Organizações, como a The Nature Conservancy (TNC) e o Instituto do Homem e Meio Ambiente da Amazônia (Imazon)

A gestão ambiental está diretamente relacionada responsabilidade social da empresa, conforme definição do autor Denis Donaire (1999, p.20), a responsabilidade social implica um sentido de obrigação para com a sociedade, assumindo diversas formas, entre as quais se incluem proteção ambiental, projetos filantrópicos e educacionais, planejamento da comunidade, equidade nas oportunidades de emprego, serviços sociais em geral, de conformidade com o interesse público. 
Figura 4: exemplo de educação ambiental

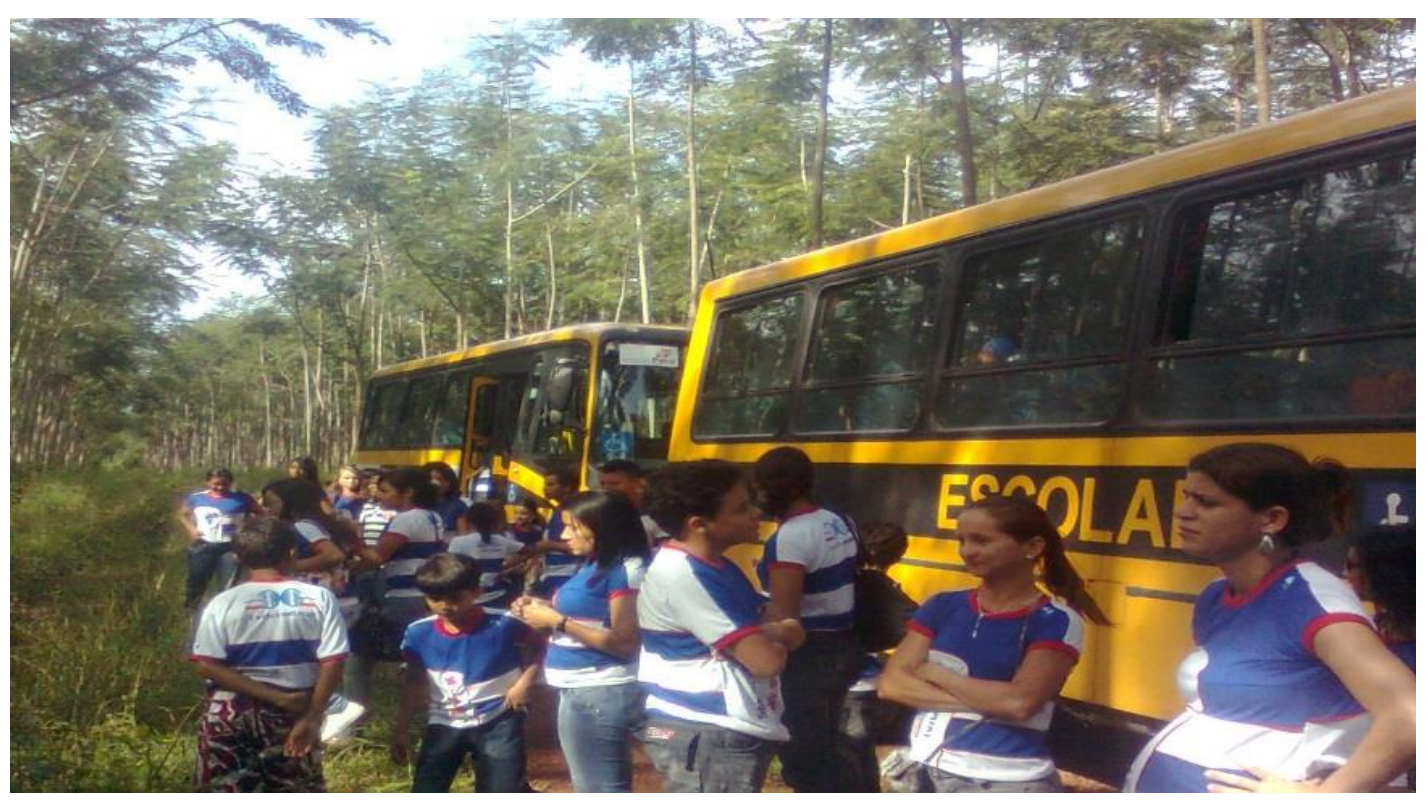

No Parque Ambiental de Paragominas, alunos do sistema público de ensino recebem aulas de educação ambiental. $O$ espaço, antes uma propriedade privada jogada à própria sorte, foi reformado, e sua vegetação, recuperada. Fonte da imagem blog HISTÓRIA É VIDA, 14 Maio de 2011.

\section{REEDUCAÇÃo SUSTENTÁVEL DIA A DIA}

Impregnar nosso cotidiano de práticas sustentáveis é um dos caminhos a serem percorridos para preservar a qualidade de vida das presentes e futuras gerações, a educação ambiental é vista hoje como uma das mais importantes iniciativas no processo de conscientização e formação ética de valores socioambientais para a sociedade como um todo.. Simples atitudes para o manejo sustentável de papéis, alimentos, resíduos, água e afins são passos importantes que contribuem para uma sólida mudança planetária, a Educação Ambiental tem que desenvolver teorias e práticas para ser crítica, transformadora e emancipatória; construir conhecimentos, habilidades, valores e atitudes, além de preparar pessoas para a participação efetiva na formulação e condução de seus destinos que muitas vezes apontamos para fora e não nos damos conta de que, primeiramente, nossa "lição de casa" deve ser feita e o exemplo deve ser dado e reafirmado diariamente. 


\section{TEMPO DE TRANSFORMAÇÃO}

Uma revolução completa, como a ocorrida em Paragominas, não acontece sem que alguns setores se sintam prejudicados. No caso do município, os "afetados" foram os produtores ilegais de madeira e carvão vegetal. Paragominas chegou a viver dias de guerra em novembro de 2008. Exploradores ilegais se revoltaram com a apreensão de caminhões de madeira e outros produtos. Em resposta, incendiaram a sede do Ibama e por pouco não lincharam os funcionários do órgão. A situação gerou até mesmo a visita do então ministro do Meio Ambiente, Carlos Minc, à cidade.

A resposta que o município deu aos incidentes foi o fortalecimento do pacto. O prefeito Demachki promoveu mais encontros com a população - e, com eles, teve a certeza de que a maior parte dos moradores estava a favor do Município Verde.

Figura 5: Plantio de novas árvores

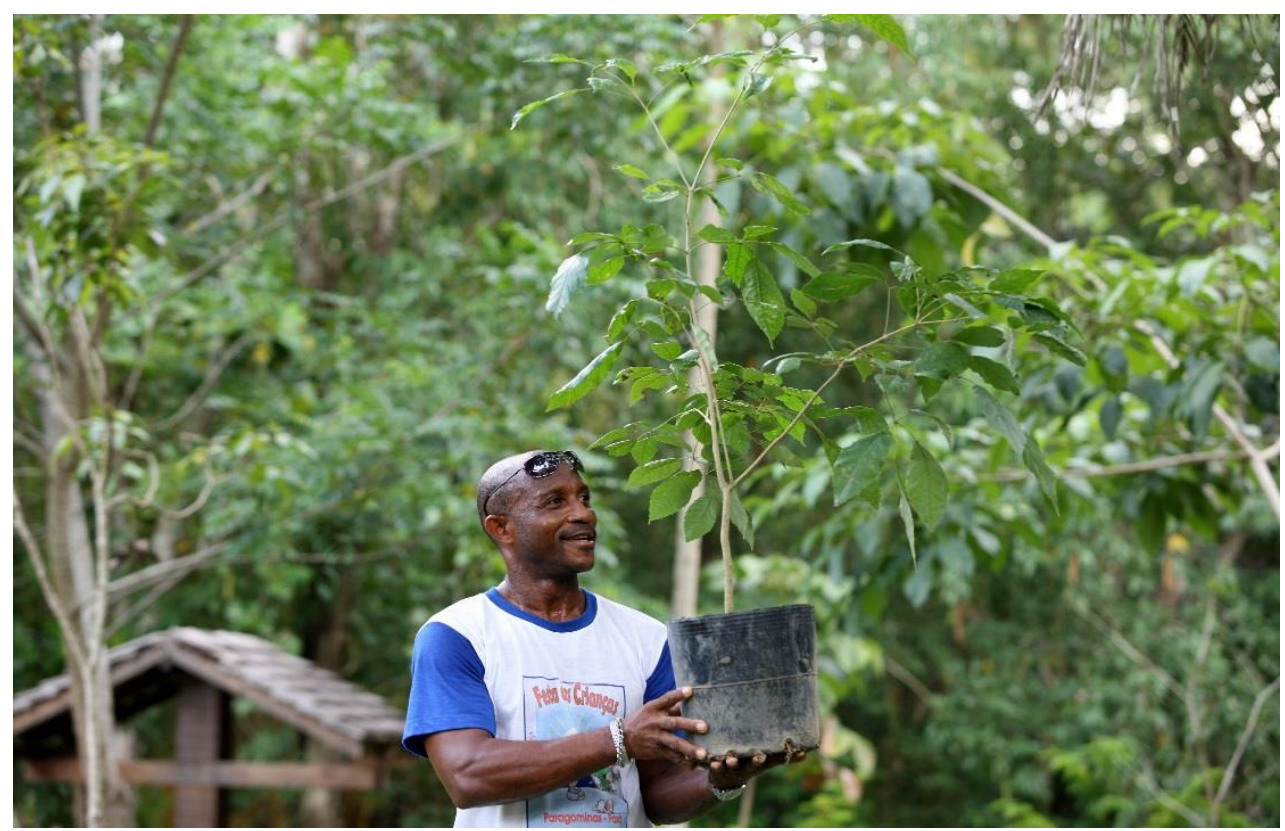

Paragominas 25 de junho de 2012.

A Gestão de Paragominas teve um grande pacto social. Em primeiro lugar houve a busca o desmatamento zero. A partir daí, houve a procura de produtos legais e sustentáveis, que fossem ambientalmente corretos (produzidos em área sem desmatamento), socialmente justos (sem uso de trabalho degradante) e enfim, 
economicamente viáveis. Os trabalhadores deixavam de trabalhar em atividades como extração ilegal de madeira e produção de carvão vegetal no longo prazo, a alteração foi favorável à cidade

\section{PARAGOMINAS COMO EXEMPLO DE CONSCIENTIZAÇÃO SOCIOAMBIENTAL PARA TODO O PAÍS}

Em maio DE 2012, o senador Aécio Neves (PSDB-MG) esteve em Paragominas. Conheceu as iniciativas ambientais do município e falou sobre o Município Verde, destacando que Paragominas é um exemplo para o Brasil inteiro. Esse exemplo se deve à força de articulação de suas lideranças políticas e do esforço da comunidade de compreender o que era preciso ser feito, mostrando que é possível e, mais do que isso, é necessário compatibilizando desenvolvimento econômico com sustentabilidade ambiental.

O parlamentar ressaltou que impressiona, em Paragominas, o envolvimento de toda a população na busca pela conclusão do projeto. A união dos moradores, segundo Aécio, demonstrou que a política pode "com responsabilidade e seriedade, competência, ética e ousadia, transformar para melhor a vida das pessoas."

10.1 COM ESSA PRÁTICA DE SUSTENTABILIDADE, O MUNICÍPIO DE PARAGOMINAS ALCANÇOU OS SEGUINTES RESULTADOS IMEDIATOS:

- Saiu da lista do Ministério do Meio Ambiente dos municípios que mais desmatam na Amazônia, o que ajudou o município a solicitar ao Conselho Monetário Nacional facilitação na concessão de crédito rural e na produção das safras.

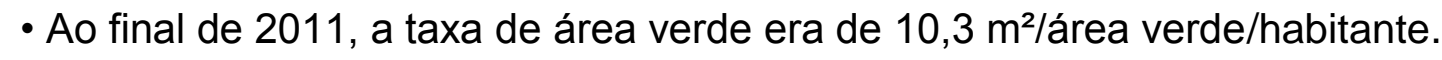

- A taxa percentual do desmatamento em relação a área total do município foi reduzindo continuamente ao longo dos anos: 0,30\% em 2008; 0,15\% em 2009; 0,17\% em 2010 e 0,032\% em 2012.

- Hoje o município conta com $66,45 \%$ de todo seu território em floresta nativa consideradas como áreas protegidas. 
- 11 hetares foram instituídos como Parque Ambiental Municipal de Paragominas, área verde com função ambiental e social.

- Alcance do desenvolvimento econômico, social e ambiental, se tornando exemplo de sustentabilidade na prática.

- Foi criado um guia para estimular os municípios na Amazônia pela Imazon, a partir da iniciativa de Paragominas, mostrando como fazer a transição para um Município Verde.

- Pelo menos outras 11 cidades paraenses já aderiram ao Programa Município Verde até 2011 e em 2014 passaram a ser mais de 50\% do total dos municípios do Estado do Pará segundo o Governo Estadual.

\section{BIBLIOGRAFIA DE REFERÊNCIA}

AGENDA 21 E AGENDA 21 BRASILEIRA GUITIÉRREZ, F.P. Ecopedagogia e Cidadania Planetária AGENDA 21 E AGENDA 21 BRASILEIRA (Ministério do Meio Ambiente)

CARTA DA TERRA, Princípios e valores para um futuro Sustentável

CASTRO, Edna; PINTON, Florence (Orgs.). Faces do trópico úmido conceitos e questões sobre desenvolvimento e meio ambiente. Belém: Cejup/UFPA- NAEA, 1997.

DALLAS, Nick. Como tornar sua empresa ecologicamente responsável: 24 lições para superar os desafios do aquecimento global (tradução de Bernardo Araújo), Rio de Janeiro, Sextante, 2009.

DONAIRE, Denis. Gestão Ambiental nas Empresas. 2 edição, São Paulo, Atlas, 1999.

GODARD, Olivier. O desenvolvimento sustentável: paisagem intelectual. In:

GUITIÉRREZ, F.P. Ecopedagogia e Cidadania Planetária

<https://conteudoclippingmp.planejamento.gov.br/cadastros/noticias/2011/8/18/paragominas-eexemplo> acesso 02/05/2015

http://municipiosverdes.com.br/ acesso 02/05/2015

<http://oglobo.globo.com/pais/mat/2011/08/20/pacto-pelo-fim-do-desmatamento-poe-paragominas-nomapa-925172632.asp > acesso 02/05/2015

<http://oglobo.globo.com/pais/mat/2011/08/22/onze-cidades-ja-seguem-modelo-de-paragominascontra-desmatamento-da-amazonia-925175224.asp > acesso 02/05/2015

$<$ http://www.orm.com.br/projetos/oliberal/interna/default.asp?modulo=247\&codigo $=548977>\quad$ acesso 02/05/2015

<http://www.paragominas.pa.gov.br/index.php?mod=article\&cat=Not\%C3\%ADcias\&article=220> acesso 01/05/2015 
$<\mathrm{http}: / /$ www.paragominas.pa.gov.br/index.php?mod=article\&cat=Not\%C3\%ADcias\&article $=236>$ acesso 01/05/2015

http://www.nature.org/ourinitiatives/regions/southamerica/brasil/destaques/com-o-apoio-da-tncparagominas-deixa-lista-do-desmatamento.xml acesso 26/04/2015

MORIN, E. Os sete saberes necessários à educação do futuro

SANTOS, M. Por uma outra globalização

Secretaria de Meio Ambiente de Paragominas (PA)

WWF. Redes: Uma introdução às dinâmicas de conectividade e da auto organização 